\title{
飛行機の主要諸元を決定する一簡易法”
}

\author{
山名 正 $*^{2>}$
}

\section{A Simple Method to Determine the chief Dimensions of Aeroplane}

\section{By Masao Yamana}

Normal gross weight $G$, weight of fuel and oil $G_{f+j}$ and necessary horsepower $N_{z}$ or thrust $T_{z}$ can readily be calculated by equations (4), (5), (6) or (10), (11), (12) respectively for propeller planes or jet planes, as the function of payload $A$, design load factor $s n_{A}$, range $R$ and maximum velocity $V_{z}$ at attitude $z$. The values of statistical constants $\alpha_{i}, b_{i}$ and numerical example are shown in appendices.

\section{1. 緒 謇}

形が与えられている飛行機の性能計算をするにはい ろいろと便利な方法为洘えられているが，初期計画の 場合には先ず棃行機つ形をきめること，すなわち“要 求性能を满足すべき最も適当な機体主要諸元”を決定 することが先決問題になる。特別な場合を除き一般的 に考えると，計画要求事項つ中で最す飛行機の要目を 左右する基本要素として，搭載物件，强度，航続距離 特よび最高速度の 4つそ探るのが妥当と思われる。そ こで先ずこの 4 要素を基として全借重量, 必要な発動 機馬力また位推力，扣よび燃料搭載量を，できるだけ 簡単な方法で求めようとするのが本報告の考え方であ る.

本方法は計算が簡単であるから, 初期計画に際し上 述の基本要素をいろいろと装えた時つ機体要目の変化 状況を調べ，最も均衡つとれた飛行機を求める等つ計 画研究に使用して便利と思わ机る。

\section{2. 言咢}

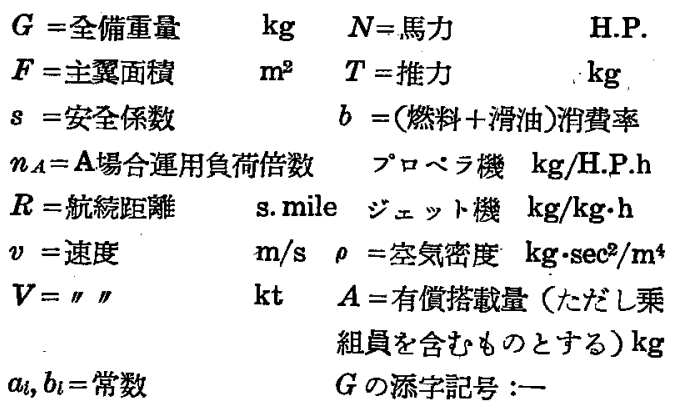

$z=$ 高度 $\quad \mathrm{km} \quad z=$ 自重 $\quad c$ =冷却装置

$C_{z}$ =揚力係数 $\quad t=$ 搭載量 $\quad f=$ 燃粼

$C_{x}$ =抗力係数 $\quad e=$ 発重材機 $\quad a=$ 滑油

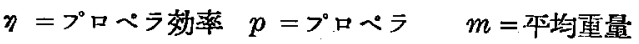

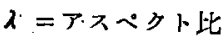

\section{3. プロペラ機の場合}

$\mathrm{A}$ 埸合の破湲角荷倍数 $\mathrm{s} n_{A}$, 航続距離 $R$, 高度 $z$
に括ける最高速度 $V_{z}$ 扎よび有償搭载量 $A$ を与て 全備重量 $G$, (燃料十滑油)搭載量 $G_{f+o} お$ よび高度 $z$ に打西必要発動蟣馬力 $N_{z}$ を求める。

構造重量 $\left(G_{z}-G_{e+p+c}\right)$ と $s n_{A}$ との間には統計的 に次式が成立する(附録参照),

$$
\left(G_{z-} G_{\theta+p+e}\right) / G=a_{1}+b_{1} s n_{A}
$$

雨辺を 1 から引いてこれを $B$ と置けば,

$$
\left(G_{t}+G_{e+2+0}\right) / G=1-a_{1}-b_{1} s n_{A}=B
$$

よって $\left(G_{t}-G_{f+o}\right)+G_{e+p+c}+G_{f+o}=B G$.

$\left(G_{t}-G_{f+o}\right)$ は搭載量加 (燃料十滑油) の重量委引 一いたものですなわち $A$ に等しく，また $G_{e+p+c}$ は概 ね発重機力公称高度に招け百公称馬力 $N_{z}$ に比例する から $G_{e+p+c}=a_{2} N_{z}$ と置けば

$$
A+a_{2} N_{z}+G_{f+o}=B G
$$

次に, 馬力の釣合式を重量つ釣合式で割れば

$75 \eta N / G=v C_{x} / C_{z}$ したがって $v / N=75 \eta C_{z} / G C_{x} ;$ 航続距離は（速度×航繶時間）とであるから $R=v \times$ $G_{f+o} / N$, これに上の $v / N$ を代入して、 $G$ を全航程の 市均重量 $G_{m}$ と考之るる

$$
\begin{aligned}
R=75 \eta C_{z} G_{j+o} / b C_{x} G_{m}(\mathrm{~m} / \mathrm{s} \cdot \mathrm{h}) & =270 " / "(\mathrm{~km}) \\
& =146 " / "(\mathrm{~s} \cdot \mathrm{mile})
\end{aligned}
$$

したがって

$R=146\left(\eta C_{z} / b C_{x}\right) G_{f \neq 0} /\left(G-\frac{1}{2} G_{f+0}\right)$ s.mile $\cdot(2)$

な拭式中の $\eta C_{z} / b C_{x}$ は巡航速度で全航程を飛んだ時

の平均值をとるものとする。

最高速度は馬力つ釣合式 $v_{z}{ }^{3}=75 \times 16 \rho_{0} \eta N_{z} / \rho_{z} C_{x} F$ において $F C_{x} / \eta=a_{3} G$ と置きかつ速度を $\mathrm{kt}$ 単位で 表わせば

$$
V_{z}^{3}=8813\left(\rho_{0} / \rho_{z}\right)\left(N_{z} / a_{3} G\right) \cdots \cdots(3)
$$

(1)，(2) 怙よび (3) の連立方程式を解いて未知数 $G, G_{j+o}$ および $N_{z}$ を求めると 
ただし

$$
\begin{array}{ll}
G=A /(B-C-D), \mathrm{kg} \\
G_{f+o}=C G, & \mathrm{~kg} \\
N_{z}=D G / a_{2} & \text { H.P. }
\end{array}
$$

$$
\begin{aligned}
& B=1-a_{1}-b_{1} s n_{A} \\
& C=1 /\left(\frac{1}{2}+146 \eta C_{z} / b C_{x} R\right) \\
& D=\left(a_{2} a_{3} / 8813\right)\left(\rho_{z} / \rho_{0}\right) V_{z}^{3}
\end{aligned}
$$

登動機が与えられてたさき

$$
\begin{aligned}
& G=\left(A+G_{\ell+p+e}\right) /(B-C), \\
& G_{f+o}=C G
\end{aligned}
$$

(4) 及び (5). 式で明らかなよ $5 k ， a_{1}+b_{1} s n_{A} ， a_{2}$, $a_{3}$ および $\eta C_{z} / b C_{x}$ に蔎計しよ弓とす西飛行機に適当 した値を入礼ると $G, G_{f+o}$ おひび $N_{z}$ 为淔ちに計算で きる・立たこ礼らの式は上の諸因子および $A, V_{z}$ $R$ 等によっ $C, G, G_{f+0}, N_{z}$ 力湾化する状況を簡明 に示す. たとえば $R$ だけを变数とした場合， $R$ と $G$ の関係任第1図つようになる。すなわち仮に現在の技 術水淮で得られる曲線をI とすれば，棈造材料または 構造法の進步にようて $a_{1}+b_{1} s n_{A}$ が小さくなるか, 発 動機の進步により $a_{2}$ 或はbが小さくなるか，さらに 室気力学の進步により $a_{3}$ が小さくなりまたは $C_{z} / C_{x}$ が大きくなること等によって II の曲線か得られるこ とになり，Iょりひ小さいＧすなわら小さい飛行機 で同じ航続力 $R$ が得られ或は $G$ を同一にすれい゙大き な $R$ が得られる. 本例注定性的な記述に過ぎないが，
この種の数値計算に 上る検討が上式に上 り容易に遂行し得る わけである。

\section{4. ジェット機の}

場合

発動機重量と公称

推力との関係を

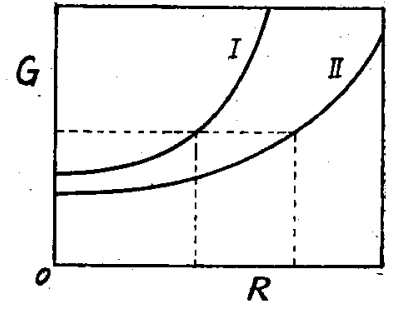

第 1 図
$G_{t}=\alpha_{2} T_{z}$ と置けば（1）と同様にして

$$
A+\alpha_{2} T_{z}+G_{f}=B G
$$

を得る・ただしジェット発動機の滑油消費量法小さい ので省略した。また $G / T=C_{z} / C_{x}$ および $V=(3.6$

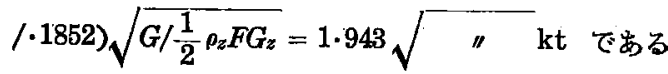
から

$$
\begin{aligned}
R= & V \times G_{f} / b T=7 \cdot 77 \sqrt{\rho_{0} / \rho_{z}} \\
& \times\left(C_{z}^{3.5} / b C_{x}\right)\left(G_{f} / G_{m}\right) \sqrt{G_{m} / F} \cdot \cdot(8)^{3,}
\end{aligned}
$$

ただし $G_{m}=G-\frac{1}{2} G_{f}$, また

$$
V_{z}^{2}=60 \cdot 3\left(\rho_{0} / \rho_{z}\right)\left(T_{z} / a_{3} G\right) \cdots \cdots \cdot(9)
$$

よってプロべラ゙機の場合之同様に

\begin{tabular}{|c|c|}
\hline プロ ララ 機 & ジェット機 \\
\hline $\begin{array}{c}C_{z_{0}}=\sqrt{e \pi \lambda C_{x p}} \\
\left(C_{z} / C_{x}\right)_{\max }=\frac{1}{2} \sqrt{e \pi \lambda / C_{x p}}\end{array}$ & $\begin{aligned} C_{z_{0}} & =\sqrt{\frac{1}{3} e \pi \lambda C_{x p}} \cdots \cdots \cdots \cdots \cdot(13) \\
\left(C_{z}^{0.5} / C_{x}\right)_{\max } & =3^{\frac{3}{4}}(e \pi \lambda)^{\frac{1}{4}} / 4 C_{x p} \frac{3}{4} \cdots \cdots(14)\end{aligned}$ \\
\hline$\frac{C_{z} / C_{x}}{\left(C_{z} / C_{x}\right)_{\max }}=\frac{2 \gamma}{1+\gamma^{2}}$ & $\frac{C_{z}^{0.5} / C_{x}}{\left(C_{z}^{0.5} / C_{x}\right)_{\max }}=\frac{4 \gamma^{0.5}}{3+\gamma^{2}}$ \\
\hline
\end{tabular}

$$
\begin{aligned}
G & =A /\left(B-C_{J}-D_{J}\right), \\
G_{f} & =C_{J} G, \\
T & =D_{J} G / \alpha_{\Omega},
\end{aligned}
$$

ただし

$$
\begin{gathered}
C_{J}=1 /\left(\frac{1}{2}+7.77 \sqrt{\rho_{0} / \rho_{z}}\left(C_{z}^{0.5} / b C_{x} R\right) \sqrt{G_{m} / F}\right) \\
D_{r}=\left(a_{z} a_{3} / 60 \cdot 3\right)\left(\rho_{z} / \rho_{0}\right) V_{z}^{2}
\end{gathered}
$$

発動機からちえられたときは

$$
\begin{aligned}
G & =\left(A+G_{e}\right) /(B-C) \\
G_{f} & =C_{J} G
\end{aligned}
$$

今 $C_{x}=C_{x p}+C_{z}^{2} / e \pi \lambda$ と置き, $R_{\max }$ 它与る $C_{z}$ を

$C_{z_{0}}$ で表わしまた $C_{z} / C_{z_{0}}=\boldsymbol{\gamma}$ と置いて $R$ に関俰する 各種係数をプロペラ機とジェット機つ場合につき比較 すれば
ブロべラ機では $R$ を大きくするには $\left(C_{z} / C_{z}\right)_{\max }$ を 大きくしまた巡航時の $C_{z} / C_{x}$ が $\left(C_{z} / C_{x}\right)_{\max }$ 上りあま り小さくない範囲で飛べばよい，( $\left.C_{z} / C_{x}\right)_{\max }$ を大き

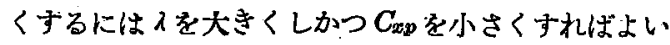
が，(14）で示されるる如くこれらはいずれも同一の次数
で利く.しかるにジェット機の場合は $\left(C_{z}^{0.5} / C_{x}\right)_{\max }$ が 大なるを要しこ礼に対してれは $\frac{1}{4}$ 乗，C品は $\frac{3}{4}$

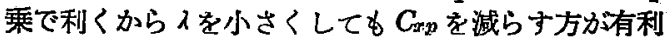
になる. 吻論飛行機全般として考えると端的々結論を 下すことは出来ないが，(14）。関係式はジェット機と 
ロベラ機に对する形態上の大きな相違点を指向するすため (15) の関係式を第 2 図に示した. のではないかと考えられる。なお計算に便ならしめる

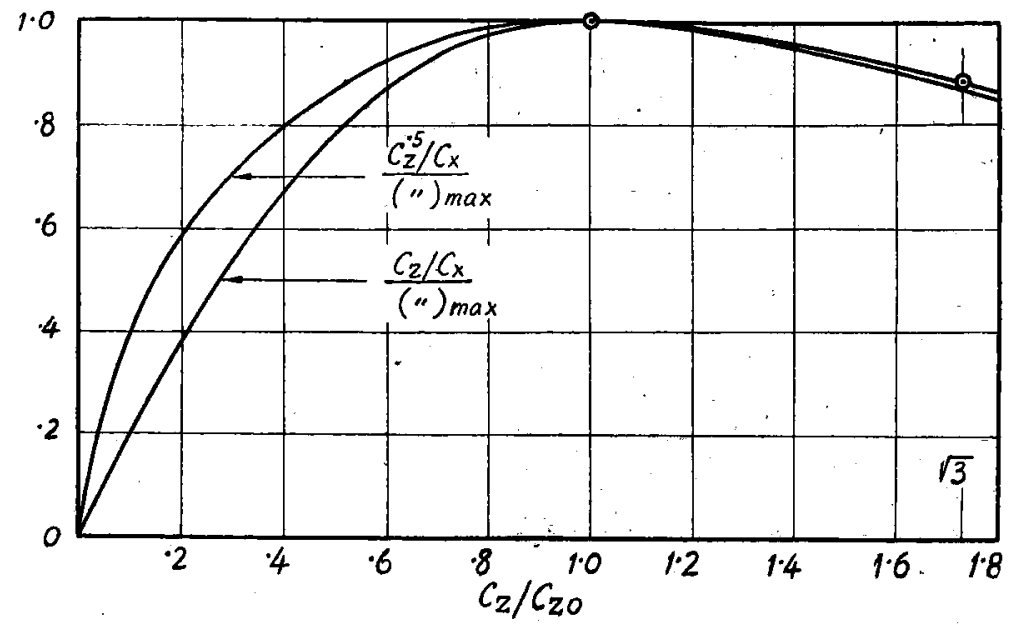

\section{6. 附錄}

$a_{b}, b_{b}$ 等は計画しよ弓 とする飛行機に対し適当な值 を探用すれはばよい方゙ここの資料にするため昭和 14 年 頃から 20 年にか仔て海軍機につき調べた値があるの でこれを以下に示す。これらの值は必要に応じその都 度求めたもので今から見ると統一が取れていなかった り，記入すべき機体为泊れていたり不備な点があるが， 現在では補足し得ないりのが多いので，手許にあるむ のをその佂記すこととした。な打第 3 図乃至 5 図中に 記した略符号々機体名称の関係は次の通りである。

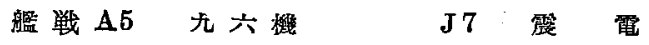
A6 零 戦夜戦 J1N1 月光 A7 裂風 D4Y2-S禁㞗 戦 $\mathrm{J} 2$ 霞 電艦㑑 $\mathrm{O} 6$ 彩 雲 N1K1-J紫 電 艦 攻 92KK 九二艦攻 N1K2-J柴電 改
第 2 図

$$
\begin{aligned}
& \text { 97-1KK无立，一 爆 D4Y4彗 星 } \\
& \text { 昘艦攻 P1 銀 河 } \\
& \text { 97-2KK元七，二水值 95ST 九五水值 } \\
& \text { 景艦攻 E12A，N } \\
& \text { B7 流星 } \\
& \text { 十二斌二座水㑑 } \\
& \text { G4一式旡攻．99 九九飛行艇 } \\
& \text { G8 連山 H8 二式飛行解 }
\end{aligned}
$$

艦爆 94KB 九四艦爆

隋傎 R2 景 笻

外国機については信賴出来る資料が少いので，木村 呚授から藏いた資料を元にしてジェット機数機につき 計算した値豕記入しておいた。

第 3 図に $s n_{A}$ と $a_{1}+b_{1} s n_{A}$ との関保を示す。

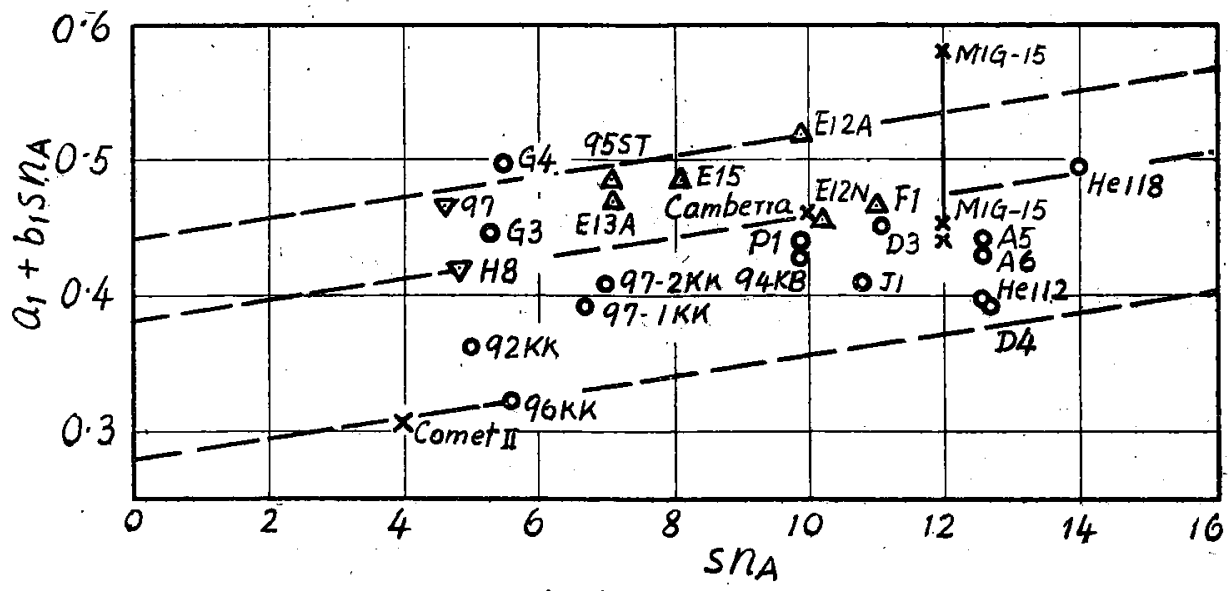

第 3 図 
×ット機住 $s n_{A}$ 力明確でないので推定して記入した。 MIG-154) の值が 2 つあるが，上の $\times$ は $G$ に对し combat weight を下の $\times$ は maximum weight を 当て䈈めたものである.|旧海軍機を较観しこれから統 計式を作狆ば
(陸上機: $a_{1}=\cdot 28 \sim .44$, ただし単発機は.28〜 ·3； 水上機お上び飛行艇: $a_{1}=.38 \sim .44$

$$
b_{1}=.0075 \text { を得る, }
$$

$a_{2}=G_{e+p+c} / N_{z}$ は発動機の公称高度 $z$ に上って異 なる. 右辺中の $G_{e} / N_{z}$ につき昭和 20 年頃迄の 1000 乃至 3000 ，馬力級発動機の概略値を示せば

\begin{tabular}{c|c|c|c|c|c}
$z \quad \mathrm{~km}$. & 0 & 2 & 4 & 6 & 8 \\
\hline$G_{e} / N_{z} \mathrm{~kg} / \mathrm{H} . \mathrm{P}$. & $.45 \sim .50$ & $.46 \sim .54$ & $.49 \sim .58$ & $.52 \sim .62$ & $.58 \sim .65$
\end{tabular}

第 4 図は $\eta C_{z} / b C_{x}$ と $R$ およびCの関係を示す。機 体略符号の傍に附した数字 は速度と高度で，たとえば 180-4 は高度 $4 \mathrm{~km}$ 巡航速 度 $180 \mathrm{kt}$ を示す. 概初 $\eta / b=3 \sim 4, \eta C_{z} / b C_{x}=30 \sim$ 60 である.

第 5 図の縀軸 $10^{3} a_{3}=$ $\left(F C_{x} / \eta\right)\left(G / 10^{3}\right)$ は全備重 量 1 ton 当りの最高速度時 に於ける抵抗面積 $\mathrm{m}^{2}$.であ って，楠軸はプロべラ機は 試作年度で爾後改造された 機体もすべて最初の試作年 度に対し記入した．海軍機 の値はすべて旧海軍第一校 行倣飛行実験部に於ける性 能試験成樍を基焚として計 算したものであって，。印 のすのの及性能計算值から 算出した. ジェット機に対 しては橫軸に初飛行年度を 探った. MIG-15 が 2 点 あるのは第 3 図と同一理由 に上る。

$a_{3}$ と $\eta C_{z} / b C_{x}$ 或は $C_{z}{ }^{\cdot 5}$ $/ b C_{x}$ はいずれる適当と思 われる值炎探用するのであ るがここれらは互に関連加 あるわけであるから，一応 検討して矛盾しない値に修 正しておく必要がある.プロペラ機つ場合につき次に そつ要領の一例を示す。

$$
\left.\begin{array}{l}
10^{3} a_{3} \stackrel{\eta, F}{\longrightarrow} C_{x} \\
V_{\max }, G / F \longrightarrow C_{z \max } \stackrel{\lambda, \varepsilon}{\longrightarrow} C_{x t}
\end{array}\right\} C_{x p}=C_{x}-C_{x t}
$$
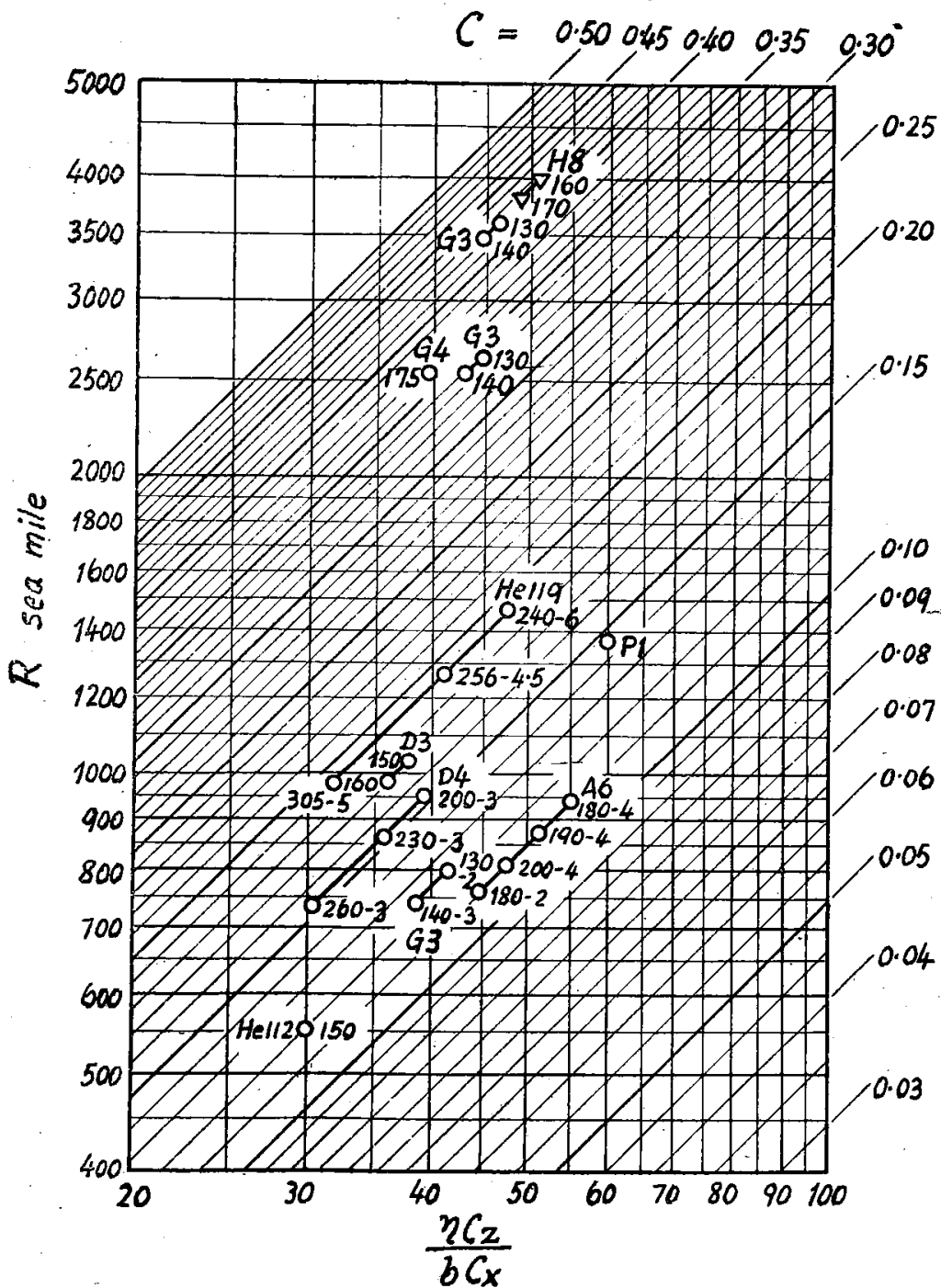

第 4 図

$\left.\begin{array}{l}C_{x p} \longrightarrow C_{z_{0}} ;\left(C_{z} / C_{x}\right)_{\mathrm{cuax}} \\ G_{m} / F, z_{\mathrm{cr}}, V_{\mathrm{cr} \longrightarrow} \longrightarrow C_{z \mathrm{cr}}\end{array}\right\} C_{z \mathrm{cr}} / C_{z_{0}}=\gamma \longrightarrow$ $\frac{\left(C_{z} / C_{x}\right)_{\mathrm{cr}}}{\left(C_{z} / C_{x}\right)_{\max }}=\frac{2 \gamma}{1+\gamma^{2}}$ $\longrightarrow\left(C_{z} / C_{x}\right)_{\mathrm{cr}} \stackrel{\eta, b}{\longrightarrow}\left(\eta C_{z} / b C_{x}\right)_{\mathrm{cr}}$ 


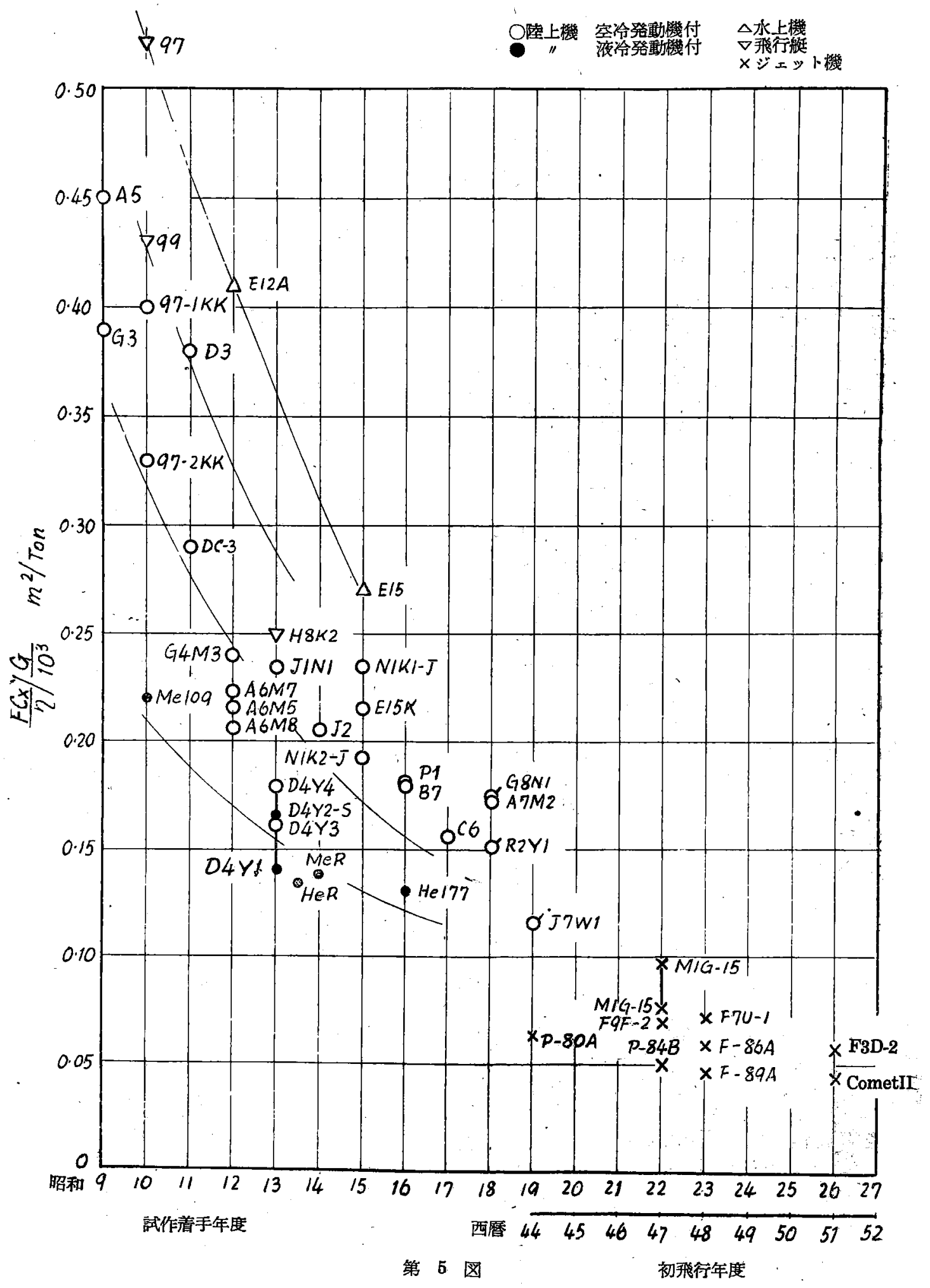


上式中添字 cr. は巡航時なること表表わす.

\section{7. 計 草 例}

空冷登動機装備の軽連絡機を考えてみる。

$A=320 \mathrm{~kg}, \quad V_{\mathrm{max}}=350 \mathrm{~km} / \mathrm{h}=189 \mathrm{kt}$ (海面上)

$R=1100 \mathrm{~km}=594 \mathrm{~s} \cdot \mathrm{mile}, \quad V_{\mathrm{cr} .}=300 \mathrm{~km} / \mathrm{h}$

$$
=162 \mathrm{kt}(Z=2.5 \mathrm{~km})
$$

$s n_{A}=1.5 \times 3.8=5.7$ とし,

$a_{1}+b_{1} s n_{A}=.475$ (やや大きな值をとる),

$a_{2}=G_{\ell+p} / N=\cdot 9$,

$10^{3} a_{3}=\cdot 25,\left({ }_{\eta} C_{z} / b C_{x}\right)_{\mathrm{cr}}=45 \quad$ とすれば

$B=1-\left(a_{1}+b_{1} s n_{A}\right)=\cdot 525$,

$C=.087$ (第 3 図で ${ }_{n} C_{z} / b C_{x}$ と $R$ の交点から),

$D=\left(a_{2} a_{3} / 8813\right)\left(\rho_{z} / \rho_{0}\right) V_{z}^{3}=\left(a_{2} a_{3} / 8813\right) V_{0}^{3}$

$=\left(.9 \times .25 \times 189^{3}\right) /\left(8813 \times 10^{3}\right)=.172$,

\& $\supset \tau$

$G=A /(B-C-D)=320 /(.525-.087-.172)$

$=320 / \cdot 266 \fallingdotseq 1200 \mathrm{~kg}$,

$G_{f+0}=C G=.087 \times 1200=104 \mathrm{~kg}$

$N_{0}=D G / a_{2}=\cdot 172 \times 1200 / \cdot 9=230$ H.P.

を得る. 今 $G / F=80 \mathrm{~kg} / \mathrm{m}^{2}$ とすれば $F=15 \mathrm{~m}^{2}$, 翼幅 を $10 \mathrm{~m}$ とすれば $\lambda \fallingdotseq .67, e=.95$ および $\eta=.80$ と しこれらを用いて $10^{3} a_{3}$ と $\left(\eta C_{z} / b C_{x}\right)_{\mathrm{er}}$ との閣係を 检討すれば

$\left(C_{x}\right)_{\text {max }}=a_{3} G \eta / F=(\cdot 25 \times 1200 \times \cdot 8) /\left(10^{3} \times 15\right)$

$$
=.016 \fallingdotseq C_{x p} \text {, }
$$

$C_{z_{0}}=\sqrt{e \pi \lambda C_{x p}}=\sqrt{.95 \times \pi \times \cdot 67 \times \cdot 016}=\sqrt{\cdot 32}=.57$

$\left(C_{x} / C_{x}\right)_{\max }=\frac{1}{2} \sqrt{e \pi \lambda / C_{x p}}=\frac{1}{2} \sqrt{.95 \times \pi \times \cdot 67 / .016}$ $=17 \cdot 7$,

また $G_{m} / F=77, V_{\mathrm{cr}}=162 \mathrm{kt}, z_{\mathrm{cr}}=2.5 \mathrm{~km}$ から $C_{z \mathrm{cr}}$ を 計算すれば, 24 を得るから

$$
C_{z \mathrm{zc}} / C_{z_{0}}=\cdot 24 / \cdot 57=\cdot 42,
$$

よって第 2 図加ら

$$
\left(C_{z} / C_{x}\right)_{\mathrm{cr}} /\left(C_{z} / C_{x}\right)_{\max }=\cdot 70
$$

したがって

$$
\left(C_{z} / C_{x}\right)_{\mathrm{cr}}=17 \cdot 7 \times \cdot 70=12 \cdot 4,
$$

$\eta \mathrm{cr}=.80$ とし $b=.22$ とすれば

$$
\left({ }_{\eta} C_{z} / b C_{x}\right)_{\mathrm{cr}}=.80 \times 12.4 / .22 \fallingdotseq 45
$$

を得る、これは最初に仮定した值と偶然一教したこと になるが，一般には一致しないのが普通であるから， どれかか要素を修正して略々一敨させればよいわけで ある゙。.

\section{7. 粘 語}

昭和 14 年頃加每年，海軍用飛行機として次年度 に試作すべき飛行機全股に対する䒠用譏試製計画（略 称実計）研究が行われ，短期間に多数機種に関する均 衡つとれた計画要求の原案を作るために，普通の方法 で性能計算をしたのでは閒に合わぬので，本報告にそ の一部を示した簡易法を使用しかなりの便宜を得た。 当時筆者に協力して資料の蕌集に努力された上山忠 夫，服部六郎，田村稫平，島文雄，中口博の諸氏並び に最近のジェット機の疽料を提供された日本大学术村 呚授に厚く御礼申上げる.

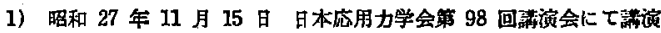

2) 阔付㪙作所

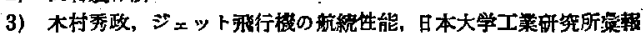

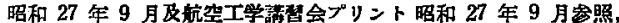

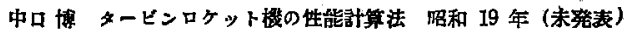

4) M.I. Gurevich, I Designed.the MIG-15, Aero Digest 1951 7. p. 17

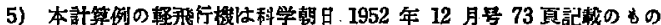
に相当する。

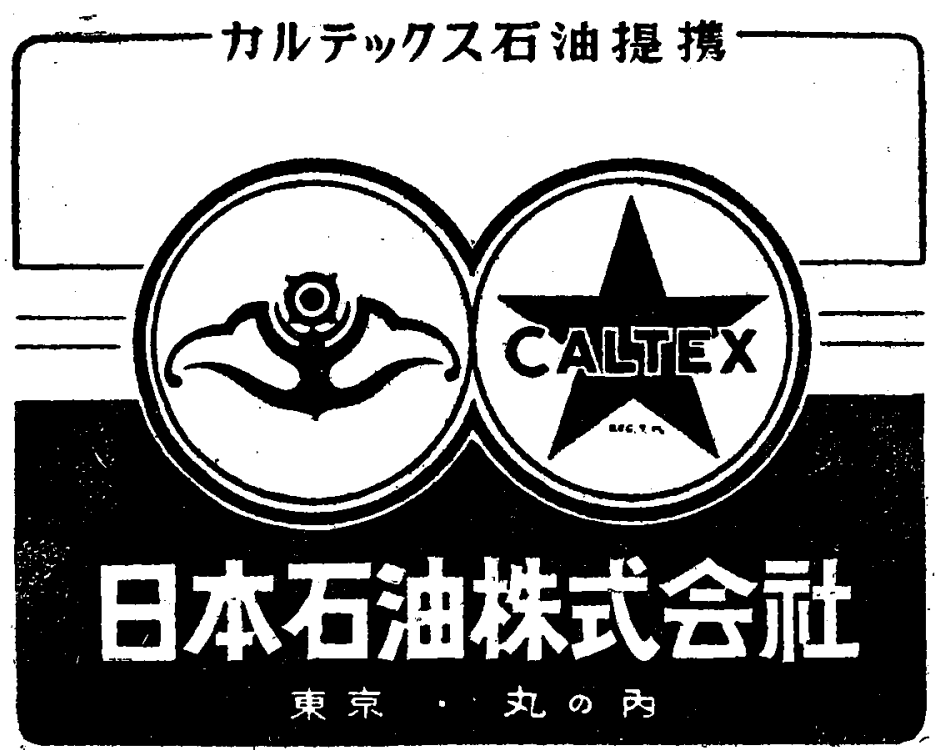

